\title{
Visões do Inferno ou o Inferno somos nós
}

Flávio Aguiar

(Universidade de S. Paulo)

Nós jä fomos auase tudo na vidạ: um outro sem eu; um eu persequido pelos (seus) outros ; um eu que na verdade era outro, ou um outro que na verdade era eu, filhos de um espaco contro verso e convulso onde de repente todo mundo era ḋo mundo todo; nös já fomos um nös em busca de eles que devian ser nös, ou que nós deviamos ser; agora penso (logo, hesito) devemos ser um nös, paciente da anomia redentora desses ült1 mos anos, em busca de um eu que passou e nos es pera, de uma outra margem, uma tha afortunada, que não sabemos qual seja, e cujo olhar jã cego para as coisas deste mundo nos contempla, com sua ironia civillzadora.

Cada cultura -na produção literäria e fora dela- ter seus motivos, temas e enredos dominan tes. Dispersas, e no entanto sclidarlamente, es sas constantes nos informam do que somos e deixamos de ser. Elas (as constantes) ou eles (os: enredos) são ao mesmo tempo fonte e depositâa rios de tmagens que se reproduzem e se multipli cam- compondo, deste lado do Atlântico e ao sul da linha demarcatôria da espécie humana, espé cie de Tordesilhas oficiosa do etnocentrismo, os processos culturais que formam a. constelação Brasil na subgalāxia das naçōes (ex-) coloniza dạs, no vastọ buraco negro, ou melhor, mestıço, que è a América Latina.

0 primelro grande enredo que nos dominou -e a passo acelerado ao lonọo do século XIX-foi o da comëdia da integração nacional.A ação deste enrecio pode ser descrita como a de arrancar a nação das sequelas e mazelas do submunco colo nial para intearä-la (fazê-la) internamente e dar-lhe um lugar entre as nações civilizadas mo dernas. No teatro, por exemplo, isso deu na comédia de costumes, tão simpätica e por vezes de uma hoa qualfdade esquecida dema1s pelos estu dlosos, onde se afirmaram ou se aflaram Pena, lencar, Azevedo, França Jr., Macedo e o crítico Machado: Entretanto foi no romance e na poesia que se cristalizou o heró1 emblemătico desse pe ricdo -o índio, que, embora quase não visite 0 teatro, flcou embalsamado nos acordes iniciais e no restante da ópera o GUAPANI, de Carlos Gomes, bode exultório (segundo a expressão feliz de Paulo Emilio Salles Gomes) que foi contracenar com os europeus no Scala de Milão. 
Nessa comëdia o "eu" nacional vive a perse guir os seus "outros" e por eles è perseguido: - primeiro "outro" -a mediocre metrópole portuquesa; o segundo "outro" -a invejada civiliza ção francesa; o terceiro "outro" -o avesso per verso, a maldita herança colonial, a escravarta, a tacanhice provinciana, a mesquinhez de uma urbaniciade mal escanhoada, o aventureirismo ganancloso em lugar da solidez burguesa de alhu res -espelhado, por exemplo, pelos aventureiros predadores do romance histórico, como Lcredano diante da casa de D.Antonio de Mariz. Eis ai a "eu" perseguicio pelos seus outros, pelo seu avesso, encravado entre alteridades.

Logo antes do predomínio desse enredó côm1 co de integração nacional, despontara un enredo que se pode compreender como uma "tragédia da alterłcade". Em meio à formação ßrcade nasciam os Cepés, Cacambos e Lindóias, de Basilio, assim como em meio aos prados, ribelros e pastoras nasciam, conforme a observação de Antonio Cạndido, as pedras, penhas e abismos da angüs tia de Clăudio Manoel da Costa. Curiosa experiência träglca, onde o natural aparece como perdido ẹm sua própria terra, e a lembrança pes soal como intrusão em paisagem alheia: artes da empresa colonial, fundadora ainda hoje de eternas miniaturas, de outros sem eu, de bonecos fa lantes.

Dentro do enredo cômico de Integração naclonal subsequente jä medravam Corpo-Santo e Ru bião, fora e dentro das páginas e maniçômios . Despontavam, portanto, os sinais da desagrega ção, o maior deles na obra do Machado maduro . Corpo-Santo desapareçeu por un século; Machado, apesar de tudo, fazia parte congênitta do enredo de Integração: Presicente primeiro e único da Acadenia Brasileira de Letras, era escritor para Castilho nenhum botar defelto ou chamar de mero primo brasilico, era um clässico da lingua.

No segundo enredo dominante, que constitui rä o ciclo seguinte, predominam impulsos de or: dem trägica, excludente, trazendo à luz o que medrava às ocultas sob o ciclo cômico da inte gração nacional: a tragédła da marginalludade. Re püblica Velha afora, esta tragédia será a do mi grante, e sua primeira realização plena è os SERTOZES, do jornalista Euclides da Cunha, onde. migrantes dos quatro cantos da miséría se reünem no Belo Monte para o massacre que, entre ou tros, condecora o peito ufano de nossa República cordial. Os ecos da trágica epopéia vêm ressoar ainda no GRANDE SERTÃO: VEREDAS, que fecha o ciclo, e MEU TIO, O IAUARETE, de Guima rāes Rosa. São balizas desse ciclo trägíco de migrante os conflitos da ocupaça da terra e o soltarem-se as amarras do crescimento urbano . Predomina nele a dialêtica entre o "velho" e 'o "novo", entre a modernidade galopante e o primi tivo, por vezes alma penada, mutante mestiço , maragunco endiabrado, por vezes criança bem nas cida que o pensamento europeu nos entrega em mãos. O Brasil migra por inteiro, tudo muaa de lugar onde antes os gaúchos gauchavam, os serta nejos sertãozavam, os jagunços jagunçavam e os politịcos adoçavam seu café com leite com mercancilas da Europa. O povo, cliente ou vizinho dos cortiços, que comesse charque ao invés de dedos e anèis.

Esta tragédia do migrante contracena com $\underline{u}$ ma 1ncipiente comëđia da urbanidade-criança. MA CUNAIMA se veste de turista aprendiz e sai a re 
definir o Brasil, terminando estrela nos braços da Imigração itallana; os gaúchos, que desapareciam no tempo, de voz anotada por Simojes Lopes Neto, acabaram por amarrar o pingo no obeIisco e outras pendências pelos cartórios e boa tes da Capital Federal, como nos conta Erico Ve rissimo; mesmo a personagem de OS RATOS, de Dio nëlio Machado, tão urbano, migra do arrabalde, de bonde, ao centro da cidade e à mägica labi rintica da roleta, à cata dos milrêis de sua in sônta; Pollçarpo Quaresma faz da migração trônts. ca via-crucis, e o que serä o amanuonse Bolmiro senão uma alma docomento expulsa de un tempo. que migrava, por inteiro, para o alem? ha Lupis cinios e Gonzanas, exilados europeus e aristo cratas antropófagos, Fabianos e Abelardos, a mi gração infernal de Graclliano nos porōes do Brg gil emerçente, hä Gețillo na Esplanada do Caste 10 em 30 e no 24 de açosto de 1954 , corpo, detonando em tragejdia sentimental a história desse eu que na vercade era outro, desse outro que na vordade era eu, fllhos de um espaço controverso e convulso onde de repente todo mundo era do mundo todo.

Nesse espaço o. Indio näo ë mais heröi," mas espalhamento Irónico; o heröl emblemätico e Prestes da Coluna, em cufa trilhaise redefine o espaço da pátría e se aglutinam as esperanças de un novo Novo Mundo,

o pröximo cirço, digo ciclo, serä prepara-: do por aquela urbanidade incipiente antes aludt. da: - ë o da comédia do nacional-popular. Neste ciclo, num Brasil fá urbanizado e que retēm a seca nordestina como pendão a redimlr, dá-se a entronização de "o povo" na cultura, logo ele ; ainda tão jovem, mal crismado em 30 e jã no reformatörio no Estado Novo em 37. Essa comédia - a do nacional-popular - galopa de crina solta tanto na fë oratöría da poesia engàjada quanto no esforço de atualização da intelígênicia da poesia de vanguarda. Ela tem também seús heröis emblemäticos: o político populista; herdeiro de um cadäver (como tambëm o é; mutatis mutandịs, o Zë Bebelo de GRANDE SERTÃO, futuro candidato a deputado e herdeiro do cadaver de Juca Ramirol; - candango que conströi Brasillia;o migrante nor dostino quo so elxa operïrio (Fablano qua comoca a gestar Lula...) o jogador de futebol que na Europa

$$
\begin{aligned}
& \text { deu un balle } \\
& \text { dançou samba } \\
& \text { e trouxe a cona... }
\end{aligned}
$$

Os grandes espetáculos desse clolo ja be apresentaram; a construção/sañração de Brasilla e a Copa de 58, na Suẻcia. Sua ação pode. ser descrita como a de integrar a nacão num movimen to ascencional de pals cronicamente subdesenvol vido e atrasado a pais moderno, com le 1 e parla mento (ate parlamentarismo), um pais homogeneamente burguês e 1ndustrializado. Sua ültima rea 11zação de vulto; embora jấ sob os coturnos da a1tadura, fol a copa de 70, quando pele, o heröt-menino de 58 , transubstánclou-se en craque-café de exportação para amerícano ver.

A comëdla do nactonal-popular deu em trag1 comédia em 64 , em Teatró do Absurdo em 68 , e nos Iinchamentos de câmara subsequentes, com a prática patética da tortura política e dos desaparecimentos: Quem reapareceu fol o Corpo-Santo e, em tendo razão, pairava söb nōs. 
A partir da Copa do Mundo de 1970 entramos em novo c1clo-enredo, durante o qual vem se atualizando o mito ancestral. do heról civiliza dor, por entre os romances e memórias da ditadu ra, o renascente indianismo de Antonio Callado, Darcy RIbeiro e outros, o restabelecimento do coloquial e o estabelecimento amplo do feminino em poesia, e a reaparição, nos comícios-mons tro, da dramaturgía da praça püblica.

Diante da anomía do consumo, do milagre, da descoberta de que nỏs, que hă uma dẻcada vallämos tanto, hoje näo valemos quase nada (0. sonho era mais valia), cresceu, a ponto de chegar à praça embora não ao paço, um começo de enredo trágico que se pode chamar de litania ou elegia pelo heról morto. Fiquemos nas mals recentes criaçōes desse nücleo mítịco: as grandes manifestações pelas diretas. 0 momento emocionalmen te culminante è ou fol sempre a evocação unísso na "daquele ou daqueles que passaram". As 1magens se embaralham na minha memörla: a multıdão cantando vandré em S.Paulo, o milhão de pessoas pisando literalmente a avenida chamada Getülio no Rio, Fafä de Belëm chamando o Menestrel das Alagoas e sua ira cordial por todo o pais... Es se "canto", ou uivo, reaparece no filme JaNĢO: , no retorno daquele anti-herōi soterrado por sua Indecisāo inflexivel, tornado subitamente melan cölico e algo grandioso em sua precariedade quando os carros adentram a ponte de paso de los Libres, üico presidente a morrer na (nossa) vala comum do exillo. Ou no FELIZ ANO VELHO, pe ca e livro, onde se espelham a busca de dols corpos, um mutilado; o outro desaparecido do universo das sensaçõ̉es.
Hä outros cantos ao lado dește, e quero destacar dols. 0 canto novamente cômico no carä ter que louva, pelos jornals, os setores de pon ta da moderna tecnologia, da informát1ca e dos video-processadores, onde se desenrolam promessas de se criar uma "nova inteligência nacional' com reserva de mercado e tudo, una espëcie de "Petrobrās para executivos". Ao lado deste ouve-se o ruido labiríntico e sulfuroso com que nestes anos de crise a limprensa liberölde descreve progressivamente a marginalidade social, agora dLvidida entre Falanges Vermelhas e Serpentes Negras.

\section{Algumas observaçōes finals:}

1. 0 círculo nuclear da produçäo cultural se alarga progressivamente, de melos estrita ou predominantemente literärios para outros de alcance imediatamente mais amplo; ao mesmo tempo, parece-me que a apropriação da palavra de alguma forma, continua a ser um dos elementos-chave dessa permanente reelaboracão dos nossos mitos de origem. Quer dizer, o acesso à palavra è con tinuamente tematizado como elemento fundamental da condição humana - mesmo quando o meio em questão não è explifitamente verbal, como è o caso da l1teratura.

2. Não è necessārío un grande esforço pa ra perceber como constante em nossos processos culturais a visão de um mundo Infero, confuso, fragmentärio, arcaico, anacrônico, ou outro adjetivo, de: onde se deseja sair ou onde è necessärto entrar em busca da contemplação ẹpifânica de algum segredo oculto que revelară, de fato, a nossa verdadelra natureza. Isso pode-se dar sob um impulso cômico (lembremo-nos de "nös",es 
tudantes/1ntelectuals que buscávamos "eles"-ope rărios da redenção com nossos míseros panfletos e como eles deviam ser nós e nós eles... lou tră gico (vejamo-nos nos comicios, a chamar alguma identidade que nos redima da anomia, o eu que se fo1 para 0 resguardo da outra margem).

3. Ao longo desses ciclos 0 inḋo -sua 1magem emblemática- è uma espëcle de termômetro. Sua nudez primitiva o situa próxima das fontes, e sua reaparição na literatura brasileira em li vros recentes Indica uma clara busca de repen sar as nossas fontes e origens. Ao mesmo tempo, o canto que vem no bojo do último cṭclo aqui 1dentificado e que penso ainda em formação, roça um motivo multo entranhado nas culturas sulame- ricanas, embora não seja exclusividade destas, Inclusive a guarani: o motivo do "heról civilızador", que, vindo de alturas ou paragens desco nhecldas, do Sol, do Ande, do Céu, semeou as formas de vida conhecidas e depois se retirou para uma outra terra (muitas vezes uma 1lha) on de espera seus conterrâneos adotivos. Do fundo de nossa anomla que, se de um lado è circunstan clal, de ouțro è congèn1ta, cristallizada nesses eus que se prestam a ser multidāo, de outros, de tus; de vocès, de eles e elas, talvez elos, sô nos resta dizer diante dos passageiros Sepés, Peris, Macunaímas, Avás, Iracemas, Lindölas, U1ą ras e Jupiras incansáveis: rogal por nós que re corremos a vós.

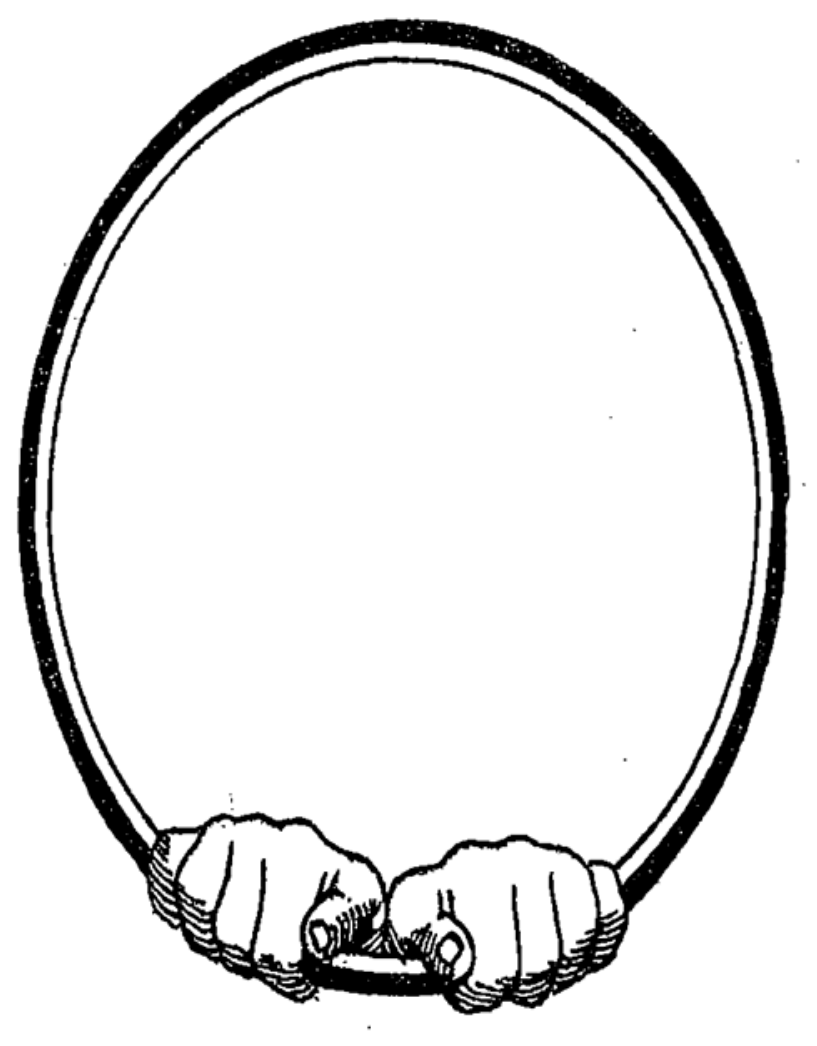




$$
0
$$

